\title{
Lawsonialnermis Extract Enhances Performance of Corrosion Protection of Coated Mild Steel in Seawater
}

\author{
H.M. Hajar ${ }^{1}$, F. Zulkifli ${ }^{1}$, M.J. Suriani ${ }^{1}$, M.G. Mohd Sabri ${ }^{2}$ and W.B. Wan Nik ${ }^{1, *}$ \\ ${ }^{1}$ School of Ocean Engineering, Universiti Malaysia Terengganu, Malaysia. \\ ${ }^{2}$ School of Fundamental Sciences, Universiti Malaysia Terengganu, Malaysia.
}

\begin{abstract}
The investigation of coating incorporated with various percentages of henna has been conducted by means of weight loss, potentiodynamic polarization and electrochemical impedance spectroscopy method. Mild steel has been studied at ambient temperature and $50^{\circ} \mathrm{C}$ in order to examine the effect of temperature. The potentiodynamic polarization measurements indicate that henna extract acts as a mixed inhibitor while the corrosion rate $(\mathrm{CR})$ value decreases as the current density $\left(I_{\text {corr }}\right)$ decreases in the presence of $10 \%$ henna extract for both temperatures. Surface and protective film analysis have been carried out using Fourier transform infrared (FTIR) and scanning electron microscopy (SEM).The inhibition activity is mainly correlated with the major active functional groups of lawsone. The main components can be found in lawsone structures are phenols $\mathrm{O}-\mathrm{H}$, carboxylic acid $\mathrm{C}=\mathrm{O}$ and alkenes $\mathrm{C}=\mathrm{C}$. The morphology of the uninhibited sample showsa rough surface of mild steel as a result of corrosion process and severe damage can be seen. In the presence of henna, a smooth surface of mild steel anda uniform deposition of henna were observed.
\end{abstract}

\section{Introduction}

The investigation of metallic structures has become important nowadays due to the industrial applications. Thus, this application processes lead to the corrosion problems. In most industries, the uses of safe constructional materials are needed. However, the amounts spent are huge. For the example of the industrial involved are oil and gas platform, ship repair, acid pickling, industrial cleaning, acid descaling, oil-well acid in oil recovery and the petrochemical processes. Due to this problem it is originates very important material and economic losses due to partial or total replacement of equipment and structures, and plant-repairing shutdowns. Corrosion is a degradation of materials' properties due to the

\footnotetext{
*Corresponding author: niksani@umt.edu.my
} 
interactions with the environments, and corrosion of most metals (and many materials for that matter) is inevitable [1].

Marine environment is probably the most aggressive environment in which metals are being to operate. The degradation of metallic surfaces due to the atmospheric corrosion is a well-known problem. Many structures exposed to this problem such as bridges, storage tanks and pipelines. Marine environments also experiencing different temperature and hence, the prediction of corrosion rate, temperature and oxygen content is important parameters that need to focus [2]. For an example, a ship is having an intense contact with seawater, but the humidity and the chloride-rich ion in seawater can be different due to the environments and surroundings. There are also the other factors that influenced corrosion rate such as salinity, $\mathrm{pH}$, pressure and also the presence of bacteria [3]. Since the technology has been developed, there are many methods to overcome this problem. One of the effective methods is coating with the corrosion inhibitor which is consist of a chemical compound that able to slower corrosion rate. Corrosion inhibition can be achieved by the addition of a chemical compound that inhibits the oxidation of the metal. The chemical inhibitor added to the system may be in the form of a liquid or vapor or both. The two steps involved in the action of the corrosion inhibitor are the transport of the inhibitor to the metal surface and the interaction of the inhibitor with the metal surface [4].

Mild steel is used widely for major infrastructure in or around seawater harbors, for shipping and offshore structures. The corrosion of structural steel is an electrochemical process that requires the simultaneous presence of moisture and oxygen. Protection using coatings or cathodic protection systems or both can be effective if properly maintained [5].

Nowadays, anti-corrosion paint is applied to the ship hull andthe other ship parts in order to reduce corrosion rate [6]. Organic coatings are widely used to prevent corrosion of metal structures due to their ease of application at reasonable cost. Coating efficiency is dependent on some intrinsic properties of the organic film (barrier effect and the presence of inhibitors or sacrificial pigments) and the metal or substrate interface interaction in terms of adherence [7].

Plant extracts are rich sources of ingredients which have very high inhibition efficiency, due to the presence of heterocyclic constituents like alkaloid and flavonoid [8]. The extracts from plant leaves, roots and seed have been studied and found to be cheap, environmental friendly and good corrosion inhibitors [9]. Henna consists of four main constituents which are Lawsone, gallic acid, $\alpha-\mathrm{D}-$ Glucose and tannic acid. These four constituents could combine with the metal cations and absorbed on the metal surface to protect the metal from corrosion attack [10]. Henna constituent seem to meet the basic requirements for consideration as alternative corrosion inhibitors: the ions form insoluble hydroxide, which makes it possible to use them as cathode and anodic inhibitors, they are non-toxic and relatively abundant in nature [11]. The aim of the research is to investigate the corrosion performance on mild steel coated with henna extract as organic inhibitor which exposed to the seawater. FTIR, EIS, PP and SEM methods were applied in this study.

\section{Methodology}

\subsection{Preparation of extraction}

The extraction of henna was carried out by immersion of $200 \mathrm{~g}$ of henna powder in $1200 \mathrm{ml}$ of ethanol for one week at room temperature. The solutions were filtered and residual has been removed from the solutions. Rotary evaporator (ROTAVAP) was used in order to get pure henna extract. 


\subsection{Preparation of substrate}

The specimens used in this study were mild steel grades A36. These specimens were cut into $25 \mathrm{~mm} \times 25 \mathrm{~mm} \times 4 \mathrm{~mm}$. The specimens were polished by using a polishing machine with the abrasive paper grade 100,120 and 180. The abrasive paper was used to remove the carbon oxide layer on the metal surface. Lastly, these specimens were cleaned with acetone and rinsed with distilled water.

\subsection{Preparation paint formulation}

Commercial paint of KTH $1 \mathrm{~K}$ Alkyd Finish was used. The thinner act as solvent and control the viscosity of paint directly. The paint was mixed by following the paint formulation and has been divided into 3 portions with different concentration of henna $(0 \%$, $10 \%$ and $20 \%$ ). Table 1 shows the paint formulations according to different concentrations of henna extract.

Table 1. Paint formulation for mild steel.

\begin{tabular}{|c|c|c|c|}
\hline Type of paint & $\begin{array}{c}\text { Volume of paint } \\
{[\mathbf{m l}]}\end{array}$ & $\begin{array}{c}\text { Henna extract } \\
{[\%]}\end{array}$ & Thinner [ml] \\
\hline 1 (control) & 300 & 0 & 30 \\
\hline 2 & 300 & 10 & 30 \\
\hline 3 & 300 & 20 & 30 \\
\hline
\end{tabular}

\subsection{Immersion test}

Water bath model Memmert was prepared with a specific amount of fresh water. Six beakers containing seawater then placed in the water bath. The samples were coated with different concentrations of henna extract $(0 \%, 10 \%$ and $20 \%)$ and hung inside the beaker. It was carried out for a duration of 30 days and 4 specimens from different concentrations were taken out for each 10,20 and 30 days in enclosed condition without any disturbance. The immersion test was conducted at different temperatures (room temperature and $50^{\circ} \mathrm{C}$ ).

\section{Results and Discussion}

\subsection{Fourier Transform Infrared (FTIR)}

Fourier Transform Infrared (FTIR) is a device used to obtain an infrared spectrum of absorption. From Figure 1, henna consists of major component which is Lawsone. The main components can be found in Lawsone structures are phenols $\mathrm{O}-\mathrm{H}$, carboxylic acid $\mathrm{C}=\mathrm{O}$ and alkenes $\mathrm{C}=\mathrm{C}$. The phenolic $\mathrm{O}-\mathrm{H}$ appeared at $3393.0 \mathrm{~cm}^{-1}$. The aromatic alkenes $\mathrm{C}=\mathrm{C}$ stretching frequency appeared at $1638.2 \mathrm{~cm}^{-1}$. The $\mathrm{C}=\mathrm{O}$ stretching frequency appeared at $1655.7 \mathrm{~cm}^{-1}$. Table 2 summarizes the functional groups found in henna extract.

Previous work reported that major components of henna extract are hydroxyl aromatic compounds, such as tannin and lawsone [12]. Phenol group of Lawsone would donate electron to the metal to achieve its noble state of orbit. At the same time, the metal would receive the electron to become more stable. This is indirectly retard further redox reaction and could resist metal from corrosion attack [8]. 


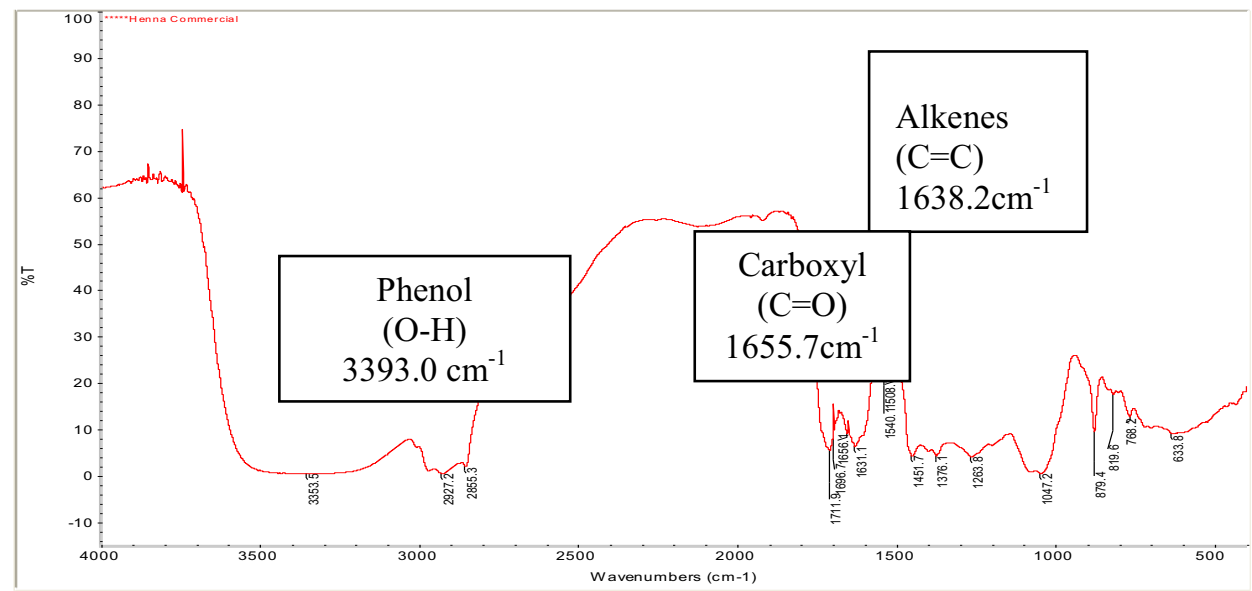

Fig. 1. Fourier Transform Infrared (FTIR) spectrum for henna.

Table 2. Main components of Lawsone identified.

Main Functional Group

\subsection{Electrochemical Impedance Spectroscopy (EIS)}

The data was presented in Nyquist plots. The $x$-axis indicates real impedance $\left(Z^{\prime}\right)$ while the $y$-axis indicates imaginary impedance ( $Z$ '). Two parameters included during the test which are temperature (room temperatureand $\left.50{ }^{\circ} \mathrm{C}\right)$ and henna concentration $(0 \%, 10 \%$ and $20 \%$.).

From the Nyquist plots as shown in Figure 2, the curves were shown by capacitive semi-circle. The shape is maintained for whole concentration and both temperature which indicates no changes in corrosion mechanism during the addition of inhibitor. Double layer capacitance $\left(C_{d l}\right)$ decreases from $8.220^{-5} \mathrm{~F}$ to $3.880^{-5} \mathrm{~F}$ for $0 \%$ of henna and $10 \%$ of henna extract respectively and increased to $5.860^{-5} \mathrm{~F}$ for $20 \%$ of henna extract at room temperature while $C_{d l}$ value at $50^{\circ} \mathrm{C}$ shows decreasing value from $3.989 \mathrm{E}^{-4} \mathrm{~F}$ to $1.352^{-4} \mathrm{~F}$ and increased to $1.6723^{-4} \mathrm{~F}$ for paint with henna of $0 \%, 10 \%$ and $20 \%$ respectively. The value of $C_{d l}$ decreased due to decreasing in local dielectric constant. It shows the absorption of inhibitor takes place on the metal surface in seawater. The values of impedance parameters were tabulated in Table 3.

The potential resistance $\left(R_{p}\right)$ increases as the concentration percentage increase, where at room temperature the $R_{p}$ increases from $193.64 \mathrm{k} \Omega$ to $409.96 \mathrm{k} \Omega$ while at $50^{\circ} \mathrm{C}$, increases from $39.90 \mathrm{k} \Omega$ to $117.74 \mathrm{k} \Omega$. However, $R_{p}$ value decreases when the henna concentration 
increases to $20 \%$ with the values of $215.75 \mathrm{k} \Omega$ at room temperature and $56.40 \mathrm{k} \Omega$ at $50^{\circ} \mathrm{C}$. Increasing $R_{p}$ leads to an increase of inhibition efficiency. Based on the result, the ratio of henna extract in the paint is found limited to $10 \%$ since it was resulting in lower value of potential resistance. Thus, increasing in the percentage of henna extract caused inhomogeneity in coating sample [13].

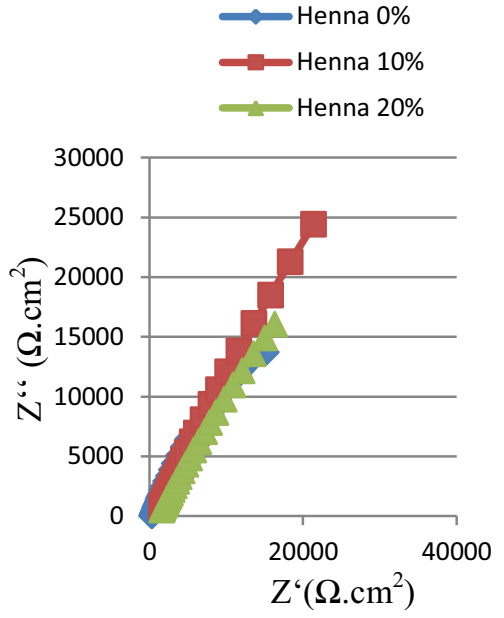

(a)

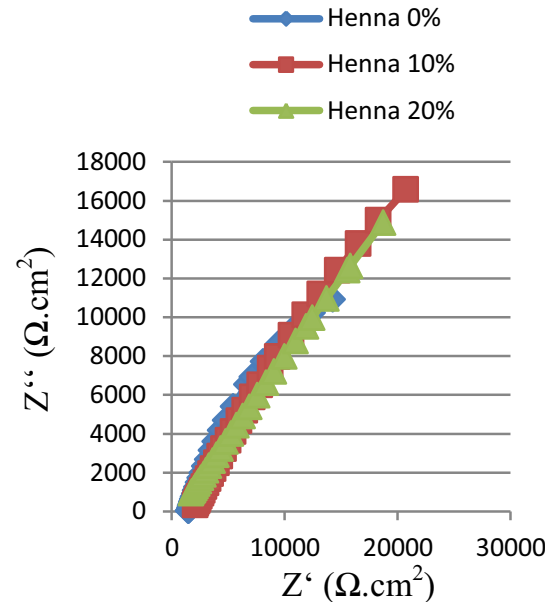

(b)

Fig. 2. Nyquist plot for 30 days (a) Nyquist plot at room temperature and (b) Nyquist plot at $50^{\circ} \mathrm{C}$.

Table 3. Impedance parameter of A36 in seawater for 30 days immersion.

\begin{tabular}{|l|c|c|}
\hline \multicolumn{1}{|c|}{ Type of Paint } & $\boldsymbol{C}_{\boldsymbol{d l}}(\mathbf{F})$ & $\boldsymbol{R}_{\boldsymbol{p}}(\mathbf{k} \boldsymbol{\Omega})$ \\
\hline Henna $0 \%$ Room Temperature & $8.220 \mathrm{E}-5$ & 193.64 \\
\hline Henna $0 \% 50^{\circ} \mathrm{C}$ & $3.989 \mathrm{E}-4$ & 39.90 \\
\hline Henna $10 \%$ Room Temperature & $3.880 \mathrm{E}-5$ & 409.96 \\
\hline Henna $10 \% 50^{\circ} \mathrm{C}$ & $1.352 \mathrm{E}-4$ & 117.74 \\
\hline Henna $20 \%$ Room Temperature & $5.860 \mathrm{E}-5$ & 215.75 \\
\hline Henna $20 \% 50^{\circ} \mathrm{C}$ & $1.6723 \mathrm{E}-4$ & 56.40 \\
\hline
\end{tabular}

\subsection{Potentiodynamic polarization}

The measurements of polarization were presented in the form of Tafel plot. From Figure 3, the results show the values of corrosion potential $\left(E_{\text {corr }}\right)$ shifted more to the positive direction as the presence of henna extract. At room temperature and at $50^{\circ} \mathrm{C}$, the $E_{c o r}$ value increase as there is presence of henna which is $-0.34368 \mathrm{~V} / \mathrm{SCE}$ to $-0.18868 \mathrm{~V} / \mathrm{SCE}$ and $0.45398 \mathrm{~V} / \mathrm{SCE}$ to $-0.38371 \mathrm{~V} / \mathrm{SCE}$ respectively. Since The $E_{\text {corr }}$ shift toward more positive direction and indicates that henna is a mixed-type inhibitor. However, the $E_{c o r r}$ value drop to $-0.30495 \mathrm{~V} / \mathrm{SCE}$ at room temperature and $0.38972 \mathrm{~V}$ as the henna percentage increase to $20 \%$. In addition of henna percentage, the corrosion potential $E_{\text {corr }}$ values shift to the range (0.12-0.16) V/SCE. The higher value of corrosion potential indicates lower corrosion rate. Corrosion potential increases as the concentration of henna extract increases. The higher values of corrosion rate are due to the thin layer formed on metal surface to protect the metal from corrosion [14]. Solomon and Umoren have studied the inhibitor used was 
effected both anodic and cathodic sites in tafel plot with $E_{c o r r}$ value towards more noble values and it suggest that inhibitor behaved as mixed-type inhibitor[15].

Table 4 shows that corrosion rate (CR) decreases when the values of current density $\left(I_{\text {corr }}\right)$ become smaller due to the lower temperature and presence of henna extract. $10 \%$ of henna extract at room temperature has lower corrosion rate than $20 \%$ of henna extract at same temperature due to the ratio of henna extract is limited to $10 \%$. According to Ostovari et al. the inhibition efficiency of mild steel increases with the increase of henna extracts concentration. As the temperature increases, the inhibition efficiency decreases [10]. Other than that, the addition of $10 \%$ henna at $50{ }^{\circ} \mathrm{C}$ decreases current density from $5.71^{-5} \mathrm{~A} . \mathrm{cm}^{2}$ to $1.02^{-5} \mathrm{~A} \cdot \mathrm{cm}^{2}$ although it was at higher temperature. This behaviour shows that henna acts as good inhibitor for corrosion of mild steel in seawater medium.

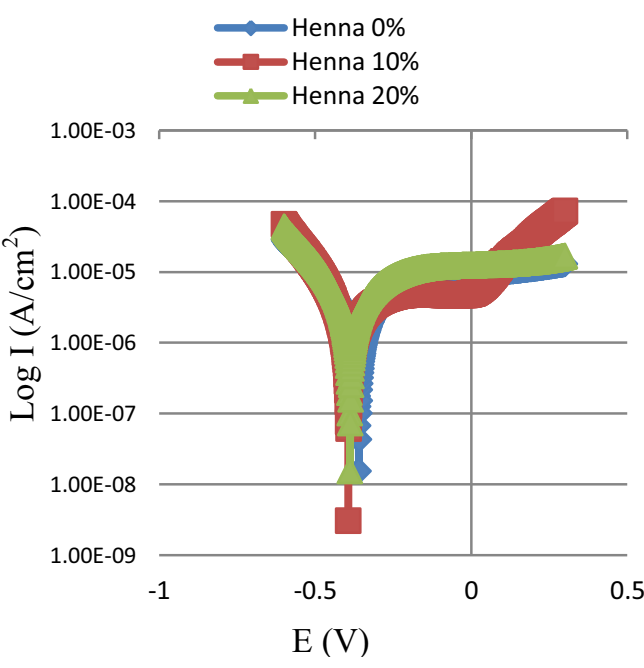

(a)

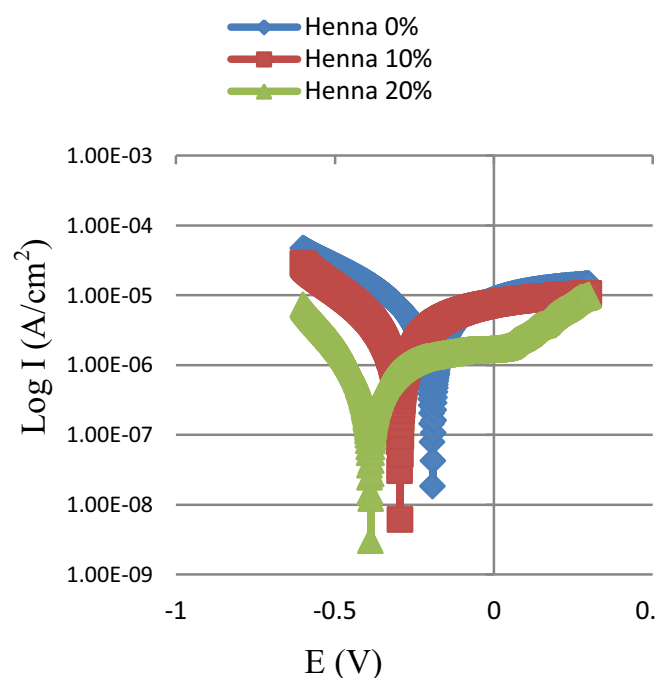

(b)

Fig. 3. Potentiodynamic Polarization of A36 in seawater for 30 days (a) at room temperature at $50^{\circ} \mathrm{C}$.

Table 4. The electrochemical parameters of A36 in seawater for 30 days at different temperatures and different henna concentrations.

\begin{tabular}{|c|c|c|c|}
\hline Type of paint & $\boldsymbol{E}_{\text {corr }}(\mathbf{V} / \mathbf{S C E})$ & $\left.\boldsymbol{I}_{\text {corr }}(\mathbf{A . c m})^{2}\right)$ & Corrosion rate (mm/year) \\
\hline $\begin{array}{c}\text { Henna } 0 \% \\
\text { Room Temperature }\end{array}$ & -0.34368 & $9.060 \mathrm{E}-6$ & 0.105230 \\
\hline Henna $0 \% 50^{\circ} \mathrm{C}$ & -0.45398 & $5.710 \mathrm{E}-5$ & 0.663880 \\
\hline $\begin{array}{c}\text { Henna } 10 \% \\
\text { Room Temperature }\end{array}$ & -0.18868 & $4.170 \mathrm{E}-7$ & 0.0048408 \\
\hline Henna $10 \% 50^{\circ} \mathrm{C}$ & -0.38371 & $1.020 \mathrm{E}-5$ & 0.118310 \\
\hline $\begin{array}{c}\text { Henna } 20 \% \\
\text { Room Temperature }\end{array}$ & -0.30495 & $5.980 \mathrm{E}-6$ & 0.069497 \\
\hline Henna $20 \% 50^{\circ} \mathrm{C}$ & -0.38972 & $1.120 \mathrm{E}-5$ & 0.130540 \\
\hline
\end{tabular}




\subsection{Scanning Electron Microscopy (SEM)}

Scanning electron microscope (SEM) was subjected to the surface of mild steel type A36 after conducting immersion test about 30 days in the absence and presence of henna (10\%) at different temperature are shown in Figures 4 and 5 respectively.

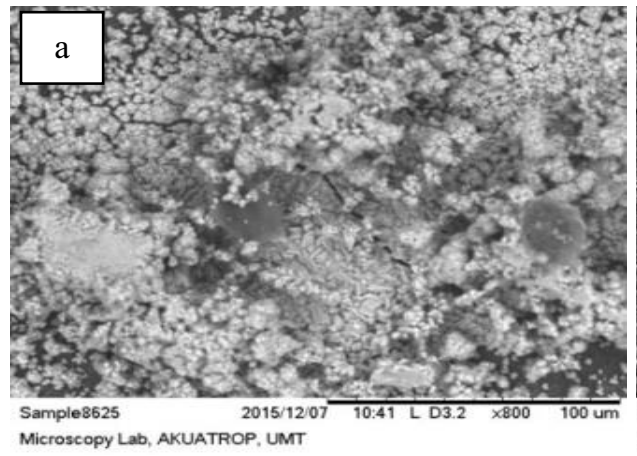

Fig. 4. SEM micrographs of the surface of A36 after 30 days immersion of paint without henna: (a) at room temperature (b) after immersion at $50^{\circ} \mathrm{C}$.
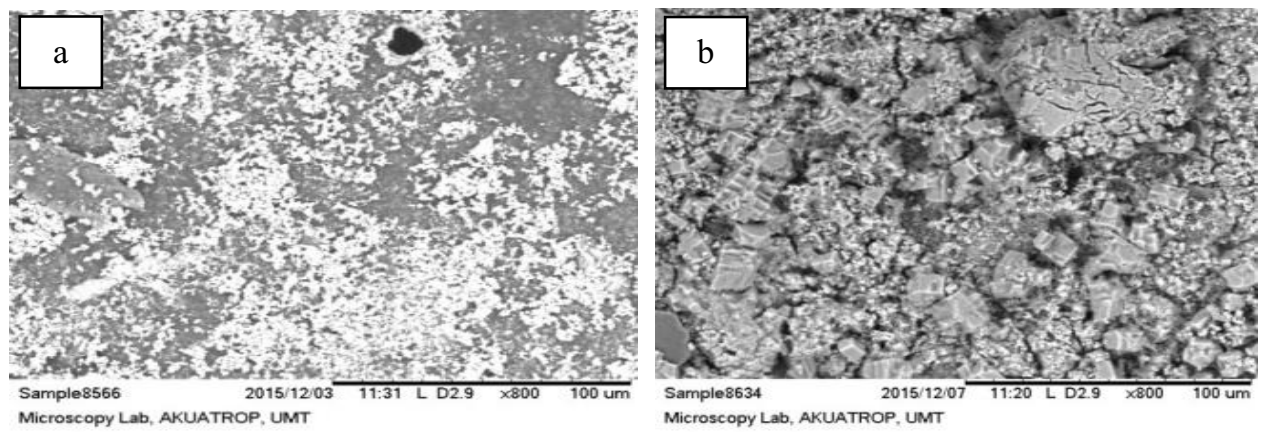

Fig. 5. SEM micrographs of the surface of A36 after 30 days immersion of paint with $10 \%$ henna extract (a) at room temperature (b) after immersion at $50^{\circ} \mathrm{C}$.

Figures $4 \mathrm{a}$, and $\mathrm{b}$ showsthe mild steel without henna extract that have very rough surface and severely damaged in every part. Serious damage on surface of mild steel was observed when the temperature increased. The presence of henna extract makes the surface transformed into smoother and more uniform deposited. From Figure 5 a, the surface was smooth and no cracks observed. The addition of henna as an inhibitor reduced the oxidation process which led to the formation of flakes or the pitting corrosion form over the surface. However, in Figure $5 \mathrm{~b}$, many cracks were observed and the surface becomes very rough. Since the ratio of henna extract is limited to $10 \%$, Figure $5 \mathrm{~b}$ shows small crack on just certain part of mild steel. When the temperature increased, the surface was rough and the cracks clearly seen.

\section{Conclusions}

As a conclusion, inhibitors play a vital role in providing protection against corrosion. The main constituent responsible for corrosion inhibitor characteristic of henna extract is found to be Lawsone. EIS measurements show that the inhibition of corrosion on mild steel is due 
to the formation of protective film on metal surface and the inhibition increases as the extract concentrations increase. As presence of henna extract, the value of potential resistance $\left(R_{p}\right)$ decreases with low protection towards mild steel and increases the double layer capacitance $\left(C_{d l}\right)$. However, ratio of henna extract is found limited to $10 \%$. Increasing in the percentage of henna extract caused inhomogeneity in coating paint sample. Besides that, the increasing in temperature caused the higher corrosion rate of mild steel. Addition of henna extract shifted the pitting potential of mild steel more positive values indicating an increased resistance to pitting corrosion. The low value of corrosion potential $\left(E_{\text {corr }}\right)$ indicates higher corrosion rate. The values of corrosion current density $\left(I_{\text {corr }}\right)$ increases with absence of henna extract. In the absence of henna extract, the surface of mild steel is very rough and severely damaged in every part while the surface transformed into smoother and more uniform deposited in the presence of henna extract. In a conclusion, henna extract is a good inhibitor for mild steel in seawater.

\section{References}

1. B.A Shaw, R.G. Kelly, Electrochem. Soc. Interface, 15(1), 24 (2006)

2. J.K. Paik, A.K. Thayamballi, Y.II. Park, J.S. Hwang, Corros. Sci., 46, 471 (2004)

3. M.T. Gudze, R.E. Melchers, Corros. Sci., 50, 3296 (2008)

4. V.S. Sastri, Green Corrosion Inhibitors Theory and Practice, (Wiley, New Jersey 2011)

5. R.E. Melchers, R. Jeffrey, Corros. Sci., 4, 1678 (2005)

6. A.S. Yaro, A.A. Khadom, R.K. Wael, Alexandria Engineering Journal, 52, 129 (2013)

7. M.A Hegazy, A.M. Badawi, S.S. Abd El Rehim, W.M. Kamel, Egypt. J. Pet., 22, 549 (2013)

8. W.B. Wan Nik, F. Zulkifli, O. Sulaiman, K.B. Samo, R. Rosliza, Mater. Sci. Eng., 36, $1(2012)$

9. V. Johnsirani, J. Sathiyabama, S. Rajendran, A.S. Prabha, International Scholarly Research Network Corrosion ISRN, 9, 1 (2012)

10. A. Ostovari, S.M. Hoseinieh, M. Peikari, S.R. Shadizadeh, S.J. Hashemi, Corros. Sci., 51, 1935 (2009)

11. M. Pourriahi, M. Nasr-Esfahani, A. Motalebi, Electronic Processing of Materials, 50, 74 (2014)

12. Moslemizadeh, S.R. Shadizadeh, M. Moomenie, Appl. Clay Sci., 105, 78 (2015)

13. Z.H.Z. Abidin, K.M. Nasir, S.K.M. Jamari, N. Saidon, S.V. Lee, Pigm. Resin Technol., 42, $128(2013)$

14. N.M. Puzai, W.B. Wan Nik, F. Manuhutu, Technical Report, Final Year Project (2014)

15. M.M. Solomon, S.A. Umoren, Journal of Environmental Chemical Engineering, 3, 1812 (2015)

16. S.N.N Jainol, W.B. Wan Nik: Study of Lawsonia Inermis (Henna) as Anti-Corrosion Coating (Paint) For Mild Steel In Seawater, Universiti Malaysia Terengganu (2016) 